\title{
SENTIDOS DAS PRÁTICAS CORPORAIS FORA DA ESCOLA PARA ALUNOS DOS ANOS INICIAIS DO ENSINO FUNDAMENTAL'
}

\author{
DR. FÁBIO MACHADO PINTO
}

Doutor em Educação (Université Paris 8, França), professor do Departamento de Metodologia de Ensino da Universidade Federal de Santa Catarina, membro do Núcleo de Estudos e Pesquisas Educação e Sociedade Contemporânea (UFSC/CNPq)

(Florianópolis - Santa Catarina - Brasil)

E-mail: fabiobage@yahoo.com.br

\section{DR. JAISON JOSÉ BASSANI}

Doutor em Educação (UFSC), professor do Departamento de Educação Física e dos Programas de Pós-graduação em Educação Física e Educação da Universidade Federal de Santa Catarina, vicecoordenador do Núcleo de Estudos e Pesquisas Educação e Sociedade Contemporânea (UFSC/

CNPq) - (Florianópolis - Santa Catarina - Brasil)

E-mail: jaisonbassani@uol.com.br

\section{DR. ALEXANDRE FERNANDEZ VAZ}

Doutor em Ciências Humanas (Universidade de Hannover, Alemanha), professor do Departamento de Metodologia de Ensino e dos Programas de Pós-graduação em Educação e Interdisciplinar em Ciências Humanas da Universidade Federal de Santa Catarina, coordenador do Núcleo de Estudos e Pesquisas Educação e Sociedade Contemporânea (UFSC/CNPq), bolsista de produtividade em pesquisa do CNPq - (Florianópolis - Santa Catarina - Brasil)

E-mail: alexfvaz@uol.com.br

\section{RESUMO}

No presente trabalho são analisados balanços de saberes e questionários de 585 alunos da quarta série de 15 escolas da rede pública de Florianópolis-SC, objetivando compreender os sentidos atribuídos às práticas corporais aprendidas fora da escola. Nossos resultados revelam que: a) elementos socioculturais marcam o sentido das práticas corporais aprendidas fora da escola; b) as práticas corporais preferidas pelos alunos, extramuros escolares, são de caráter institucional, especialmente esportes coletivos e individuais; c) apesar das dificuldades dos escolares para refletir por escrito sobre as práticas corporais, foram identificadas categorias relacionadas ao sentido dessas práticas, entre as quais predominam o sentido do prazer.

PALAVRAS-CHAVE: balanço do saber; práticas corporais; ensino fundamental; desigualdades sociais.

I. A pesquisa que deu origem ao artigo foi apoiada por bolsa de doutorado da CAPES e por uma de produtividade em pesquisa do CNPq (Projeto Teoria Crítica, Racionalidades e Educação III). A pesquisa compôs o projeto Documentação, sistematização e interpretação de boas práticas pedagógicas nos processos de educação do corpo na escola (2010-2012), financiado pelo CNPq. 
Nas últimas duas décadas tornou-se conhecida no Brasil uma abordagem investigativa no campo da Educação que tem considerado as vozes dos sujeitos, em especial dos alunos, no que se refere aos sentidos por eles atribuídos aos processos de ensino e aprendizagem. Valendo-se de uma ferramenta teórico-metodológica denominada "bilan de savoir"2 (balanço do saber), um grupo de pesquisadores inicialmente liderados por Bernard Charlot - cuja obra popularizou-se ainda mais no Brasil ${ }^{3}$ a partir da tradução, desde a década retrasada, de parte de seus trabalhos sobre o tema (por ex. CHARLOT, 2000, 200 I) - tem buscado analisar relações de crianças de famílias populares com o saber ${ }^{4}$ e com a escola e, associado a isso, a origem dos eventuais fracasso ou sucesso escolar (CHARLOT; BAUTIER; ROCHEX, 1992).

Conforme esclarece Rochex (2006, p. 640), "quando a equipe Escol se constituiu e realizou a pesquisa de que resultaria a publicação da obra École et savoir dans les banlieues... et ailleurs [Escola e saber na periferia... e em outro lugares] (Charlot; Bautier; Rochex, 1992)", empregou a noção de relação com o saber - já anteriormente utilizada por Bernard Charlot em seus estudos - e a combinou com abordagens teórico-metodológicas diversas, provindas dos campos dos estudos sobre a Linguagem e da Psicanálise, buscando um refinamento teórico-metodológico capaz de "melhor pensar e estudar a questão da produção/reprodução das desigualdades sociais na escola." (ROCHEX, 2006, p. 640). Colocava-se então a perspectiva de avançar em relação a abordagens investigativas que se debruçavam sobre a relação entre desigualdades sociais e culturais e a escola, em grande medida realizadas a partir de "visões unilateralmente e globalmente deficitárias (explicações em termos de handicap sociocultural) ou de conceitos muito gerais e hegemônicos, tais como

2. Trata-se de um instrumento de pesquisa desenvolvido pela equipe ESCOL/Université Paris 8. Este instrumento vem sendo aperfeiçoado desde 1988, quando foi aplicado em uma classe de $3^{\text {eme }}$ (equivalente ao nono ano escolar brasileiro) "Comme on fait un bilan auto, un bilan santé, faites votre bilan de savoir. (Savoir faire, savoir être)". Este balanço não tinha por objetivo realizar um inventário de tudo o que os alunos sabem, mas de definir o que eles consideram mais importante. Em 1989, ele foi novamente aplicado em turmas $6^{\text {ème }}$ ao $3^{\text {ème }}$ (quinto e nono ano escolar). O enunciado foi normatizado da seguinte maneira: "J'ai .... ans. J'ai appris des choses chez moi, dans la cité, à l'école, ailleurs. Qu'est-ce qui est important pour moi dans tout ça ? Et maintenant, qu'est-ce que j'attends ?". Os balanços continuaram a ser aperfeiçoados nos estudos de Charlot, Bautier e Rochex (1992, p. 36). Em 1992, Jean-Yves Rochex empregou o instrumento em sua tese de doutorado, publicada em 1996. Esta é a versão mais próxima desta que utilizamos em nossa pesquisa.

3. Charlot já era conhecido no campo educacional brasileiro, sobretudo no meio acadêmico, desde o início dos anos de 1980, muito em função da recepção de seu livro Mistificação pedagógica (CHARLOT, 1979), publicado na França, em 1976, e três anos mais tarde no Brasil.

4. Trata-se de uma noção-carrefour (ROCHEX, 2004), encontrada em muitos grupos de pesquisa em ciências da educação (GARNIER, 2003; JOURDAN; TERRISSE, 2005; DEVOS-PRIEUR, 2006), mas que podem ser resumidas em três: a abordagem antropológica e didática de Yves Chevallard (1998), a abordagem inspirada na Psicanálise (MOSCONI; BEILLEROT; BLANCHARD-LAVILLE, 2000) e, finalmente, a abordagem sociológica (CHARLOT, 1997; CHARLOT; BAUTIER; ROCHEX, 1992; BAUTIER; ROCHEX, 1998; ROCHEX, 1995). 
o conceito de código em Bernstein [...] ou o conceito de habitus em Bourdieu." (ROCHEX, 2006, p. 640; grifos do autor). Tais abordagens mobilizariam "visões e conceitos [...] que mal consideram a diversidade interna dos diversos grupos sociais e pouco espaço deixam para a especificidade, a produtividade e a historicidade das atividades e instituições sociais e das biografias dos agentes ou sujeitos sociais." (ROCHEX, 2006, p. 640).

Ainda que, retrospectivamente, se possam fazer objeções às pretensões daquela investigação, como faz Rochex (2006, p. 64l-643), são inegáveis os avanços metodológicos decorrentes do modo como foi abordado, a partir de estudos de caso, os processos de construção do "fracasso" ou do "sucesso" escolar em ambientes populares. A principal questão investigada por aquele grupo de pesquisadores, e que retomamos, em parte, neste trabalho, foi a de compreender quais mobiles estariam na base dos processos de aprendizagem dos saberes escolares. $\bigcirc$ balanço do saber, como instrumento metodológico, busca criar uma atmosfera na qual o aluno escreva o que sente e pensa, não desconsiderando que, estando na escola, o sentir e o pensar podem ser expressos para atender a expectativa que ele presume ser a da escola (CHARLOT; BAUTIER; ROCHEX, 1992, p. 39). Trata-se, sempre, de um discurso em situação.

O presente trabalho apresenta parte dos resultados de uma pesquisa mais ampla, na qual procuramos analisar o que está na base da mobilização para a aprendizagem de práticas corporais ${ }^{5}$ dentro e fora da escola, para alunos da rede pública de Florianópolis. Não buscamos saber da eficiência ou dos resultados dessa aprendizagem, mas sobre o que leva o aluno a se mobilizar para realizá-la. Indagar sobre o sentido é o mesmo que interrogar sobre os móbiles que fazem os estudantes agirem, o que implica também considerar aqueles que não são imediatamente fruto de reflexão, mas que podem atuar em plano mais espontâneo, ou até mesmo irrefletido. Embora consideremos que as aprendizagens não podem ser alcançadas somente a partir dos móbiles, mas também dos objetivos da ação e das operações que são realizadas para alcançá-las, focalizamos neste artigo apenas os primeiros, que agem sobre os alunos dando sentido ao aprender.

5. Mesmo reconhecendo a abrangência e a generalidade do termo, compreendemos, no âmbito dessa pesquisa, práticas corporais como aqueles dispositivos que, possuindo certa sistematicidade e recorrência histórica, tomam o corpo como território privilegiado de inserção e incisão - portanto, o tomam como objeto -, apoiando-se em um conjunto de técnicas disponíveis em um tempo, que por sua vez são organizadas segundo uma sintaxe própria, historicamente delimitado por uma tradição. São fruto também, portanto, de uma episteme (FOUCAULT, 2007), de um saber-poder que não propriamente as anuncia, mas Ihe sustenta discursivamente. $\bigcirc$ emprego desse conceito, no campo da Educação Física, no Brasil, é relativamente recente e cercado de ambiguidades. Uma breve análise sobre a utilização do termo práticas corporais na Educação Física pode ser encontrada em Lazzarotti Filho et al. (2010). 
Para tal, utilizamos o balanço do saber como estratégia metodológica, comportando as seguintes questões abertas: a) Quais são as atividades físicas ou esportivas que você aprendeu desde que nasceu e que são importantes para ti? a) Fale sobre quem as ensinou, onde e como. O balanço foi acompanhado por um questionário autoaplicável que, como aquele, foi respondido em sala de aula sob a supervisão de universitários ou professores que colaboraram com a pesquisa. O questionário, composto por questões abertas e fechadas, indagou sobre: a) a relação com a escolaridade; b) a relação com a Educação Física escolar e as práticas corporais aprendidas; c) a relação com as práticas corporais apreendidas fora da escola; d) os resultados escolares e a elaboração de si; e) um conjunto de informações socioculturais: formação e ocupação dos pais, idade escolar, sexo, autodenominação da cor da pele. ${ }^{6}$

Os dados foram coletados no ano de 2007, em 30 turmas de quarta série de 15 escolas da rede pública (5 estaduais, 9 municipais e I federal) de diferentes bairros e regiões do município de Florianópolis (SC), totalizando 585 alunos investigados, o que representa uma amostra de aproximadamente I 5\% da população escolar de Florianópolis matriculada, naquele ano, na quarta série. Empreendemos uma análise qualitativa dos dados relativos a temas como a relação dos alunos com a Educação Física e com a escola, com ênfase nas práticas corporais aprendidas em seu interior e fora dela, e uma análise quantitativa dos dados relativos à escola e outros referentes a questões socioculturais, cruzando-os, sempre que possível, com indicadores oficiais sobre a Educação no Brasil, em Santa Catarina e em Florianópolis. Nossa intenção, portanto, no âmbito da pesquisa mais ampla, é apresentar constelações nas quais os sujeitos investigados sejam analisados a partir do sentido que dão às suas atividades, aprendizagens e aos resultados escolares, mas também do contexto sociocultural em que se inscrevem. ${ }^{8}$ Entretanto, o foco do presente trabalho tem pretensões menores, na medida em que se debruça apenas sobre a análise do primeiro conjunto de resultados, mais especificamente, os balanços dos saberes sobre a aprendizagem de práticas corporais fora da escola. Os dados serão discutidos em bloco, uma vez que, salvo quando devidamente explicitado, as diferenças nas respostas dos estudantes das escolas das três redes públicas investigadas, em relação às práticas preferidas extraescolares e aos sentidos a elas atribuídos, como se verá, são pouco acentuadas.

Explorar os sentidos atribuídos pelos alunos à aprendizagem de práticas corporais fora da escola é importante porque a Educação Física e as práticas corporais

6. Utilizamos as categorias presentes nas enquetes do IBGE (Instituto Brasileiro de Geografia e Estatística): Amarelo (oriental), Branco, Indígena, Negro ou Pardo.

7. As escolas de Florianópolis não estavam ainda adaptadas ao sistema de ensino fundamental de 9 anos. Assim, a quarta série primária representava o fim dos anos iniciais. Optamos, por isso, em manter a denominação antiga.

8. Na análise dos dados utilizamos o programa Modalise e o índice de análise proposto por Philippe Cibois (1983). 
na escola se alimentam com que se aprende em casa, na rua, nos clubes, com pais, colegas e amigos, nos/pelos meios de comunicação de massa, especialmente a televisão. Da mesma forma, as práticas escolarizadas também oferecem conteúdo e forma para a experiência extraescolar.

Os alunos que participaram da investigação tinham entre 8 e 14 anos. Observamos que, em 2007, I I \% deles estavam em defasagem escolar de dois ou mais anos, ${ }^{9}$ o que representa um percentual maior do que a média brasileira, porém abaixo da de Santa Catarina e da própria cidade. ${ }^{10}$

Uma breve mirada sobre os sujeitos estudados identifica desigualdades socioculturais importantes nas populações atendidas por escolas de diferentes mantenedoras. Nas estaduais, observamos crianças de famílias mais pobres e com menos formação escolar, não brancas e com maior taxa de defasagem escolar: os que se declaram negros ou pardos somam 44,9\% (contra 33,7\% nas escolas municipais e $26,1 \%$ na instituição federal); $80 \%$ dos que se dizem "não brancos" nas escolas estaduais vivem em famílias com renda mensal estimada entre I e 2 salários mínimos e estão em defasagem escolar, ou seja, 38\% do total estudado. Estima-se que são as crianças de origem étnicoa-racial afrodescendente, em sua maioria nas escolas estaduais, as mais pobres e menos favorecidas do ponto de vista sociocultural. Num outro extremo, temos os alunos que se consideram "brancos", maioria nas três redes pesquisadas (48,8\% na estadual, 55\% na municipal e 67,4 na instituição federal). Na escola federal, $30 \%$ dos que se declaram "brancos" vivem em famílias que recebem mensalmente mais de quatro salários mínimos. Nas escolas municipais existe um maior equilíbrio entre renda familiar, nível de escolaridade dos pais e cor da pele autodeclarada pelos estudantes.

Nas próximas páginas identificaremos quais seriam estas práticas e o sentido que elas ganham fora da escola. Na primeira parte, mencionaremos as práticas corporais que são importantes para os alunos, como eles as aprenderam e com quem. Na segunda parte, esboçamos os quatro grupos de respostas extraídos da análise dos balanços de saberes, relacionadas ao sentido atribuído àquelas práticas corporais consideradas importantes fora da escola pelos alunos. Na última seção do trabalho, dedicada às considerações finais, após ponderar sobre as possibilidades e limites metodológicos dos instrumentos utilizados na investigação, retomamos os

9. É a defasagem entre a idade e a série que o aluno deveria estar cursando. Essa distorção é considerada um dos maiores problemas do ensino fundamental brasileiro, agravada pela repetência e o abandono da escola (MENEZES; SANTOS, 2011).

10. Essas duas médias incluem escolas privadas e federais que, segundo os mesmos dados do INEP, possuem baixas taxas de defasagem escolar quando comparadas às demais redes de ensino. Em 2007, o INEP registrou para a região sul 6,1\% e para Santa Catarina 4,6\%. Fonte: <http://www.inep.gov.br/>. Acesso em: 12 dez. 2009. 
principais achados, enfatizando a relação entre as capacidades das crianças de narrar sobre as práticas corporais indicadas como de preferência e as condições sociais e culturais que usufruem.

\section{AS PRÁTICAS CORPORAIS E SEUS SENTIDOS FORA DA ESCOLA}

As práticas corporais aprendidas fora da escola configuram-se como um conjunto de técnicas corporais aprendido lentamente e de forma tradicional (MAUSS, 2003, p. 407). Mauss explica que tais técnicas são resultado da produção humana e social interiorizada até os níveis mais profundos do sujeito, sem passar, necessariamente, por uma apropriação reflexiva de seu significado e importância no contexto sociocultural no qual se inscrevem. Os saberes são mediados por adultos e outras crianças que compõem o contexto, delimitando as condições pelas quais o iniciante vai fazer uso delas para satisfazer seus desejos e necessidades (CHARLOT; BAUTIER; ROCHEX, 1992). É o que acontece com as práticas corporais.

$\mathrm{Na}$ análise do balanço do saber, fizemos um levantamento das práticas corporais que são importantes para os alunos, como e com quem eles as aprenderam. Foram analisadas 585 respostas, com I .27। citações de práticas. Elas foram agrupadas, para fins de apresentação e análise dos resultados, em categorias aglutinadoras (práticas corporais esportivas coletivas e individuais, jogos tradicionais, jogos de rua, práticas corporais artísticas, práticas corporais na natureza, quase jogos, técnicas corporais de base, jogos virtuais, saber sobre as práticas) desenvolvidas sob o apoio das proposições de Dugas (2004). Em nosso estudo, os alunos se referem mais frequentemente às práticas corporais esportivas (48,4\%). Dessas, 37,8\% são coletivas e 10,6\% individuais. As brincadeiras e jogos, como os tradicionais (17,4\%), os de rua (13,3\%) e os quase jogos " (3,5\%), juntos são referidos em 34,2\% dos balanços, mostrando que o jogo, tomado aqui como categoria mais geral, também é muito importante para as crianças. São pouco relevantes neste universo as práticas corporais artísticas $(6,6 \%)$ e as atividades na natureza (I,9\%). Também foram mencionadas práticas relacionadas ao trabalho doméstico (lavar, passar, limpar, cozinhar), mas também a técnicas elementares como andar, saltar, correr, lançar, que aglutinamos na categoria técnicas corporais de base, mencionadas em 2,2\% das respostas. Como saber sobre as práticas, presente em apenas $0,5 \%$ dos balanços,

1।. Neles os participantes não se confrontam e nem buscam a vitória, de forma que sanções e recompensas não se inscrevem no contrato da contenda. Trata-se de atividades que se caracterizam pela busca do lugar social e do prazer de agir, fora de toda concorrência ou de toda disputa quer seja individual ou intergrupal, como por exemplo: caminhar, andar de roller, pedalar de bicicleta, soltar pipa, tomar banho de mar, subir em árvores etc. (DUGAS, 2004). 
foram citadas: história de uma determinada prática, regras e táticas de jogo, saberes sobre a organização e o treinamento, sobre a promoção da saúde.

As práticas corporais esportivas coletivas são as mais citadas nas respostas dos alunos, com amplo destaque para o futebol e voleibol. Em número bem reduzido aparecem outras modalidades como o basquete, handebol e até mesmo o basebol, em surpreendente aparição. Dentre os esportes individuais temos a natação, ginástica, xadrez, tênis, pingue-pongue e judô. Juntas, como referido, as práticas corporais esportivas estão presentes em quase $50 \%$ dos balanços.

Dos jogos tradicionais, os alunos mencionaram o pular corda, alerta e pegapega. Entre os jogos de rua, empinar pipa e a bola de gude foram apontados como de larga preferência, mas aparecem também brincadeiras de bastão, esconde-esconde, bicicleta e skate, futebol e basquete de rua. Os quase jogos mais citados foram jogar bexiga d'água, subir em árvores, tomar banho de mar e caminhar.

As práticas corporais artísticas mais comuns entre as crianças pesquisadas foram a dança (samba, hip-hop, pagode, street, funk), o teatro e a capoeira. As práticas ou atividades "na natureza" foram pouco citadas pelos alunos, que mencionaram escalar ou fazer rapel, mergulhar e surfar, que parecem ser pouco acessíveis às crianças deste meio sociocultural. As práticas corporais artísticas, na natureza e jogos virtuais foram menos frequentes nas respostas, em virtude, provavelmente, das exigências de recursos materiais e financeiros que não estão ao alcance de boa parte da população estudada.

Tentaremos, a seguir, esboçar algumas categorias relacionadas ao sentido dessas práticas significativas e que são consideradas importantes fora da escola. Nossa questão seria também a da forma (linguagem) como o aluno o expressa, entendendo, assim como Bautier (1995, p. 09), que a relação entre a linguagem e as produções que dela resultam interferem na construção dos saberes e nas respostas às exigências escolares, constituindo uma dimensão importante desse sentido. Trata-se, portanto, de uma análise das práticas linguajares (BAUTIER, 1995, p. 43), com a qual procuramos compreender a maneira de dizer das crianças como uma parte do sentido, bem como o conteúdo expresso, por vezes sem mediação reflexiva. Práticas linguajares são

[...] ancrées dans leur mode de socialisation familiale, composé par des valeurs, des attitudes, des représentations et des utilisations familières du langage dans leur double aspect cognitif et interactionnel, qui sont elles-mêmes liées à la trajectoire des individus et à leurs conditions de vie. (BAUTIER, 1995, p. 204). ${ }^{12}$

12. "“...] correspondentes às suas formas de socialização familiar, compostas de valores, atitudes, representações e dos usos costumeiros da linguagem, em seu duplo aspecto, cognitivo e interacional, e que estão, elas mesmas, ligadas à trajetória dos indivíduos e às condições de vida." (Tradução nossa). 
É importante registrar a enorme dificuldade dos escolares para expressar o sentido dessas práticas. 7\% dos alunos pesquisados sequer conseguiram expressar-se por escrito e, entre os que responderam, diversos tiveram o apoio de um colega de turma, que escrevia aquilo que eles ditavam para ser posteriormente copiado. Outros pediram para que escrevêssemos diversas palavras simples no quadro, para que depois pudessem copiar a maneira ortográfica correta: voleibol, basquetebol, futebol, campo, escola etc. Em todas as turmas em que aplicamos o instrumento, permitimos e incentivamos este tipo de ajuda, o que em parte, sabemos, pode ter induzido alguns alunos a escolher as palavras escritas pelos pesquisadores. Foi, no entanto, uma estratégia de viabilização do processo. Mesmo assim, uma grande parte dos balanços apresentou uma variedade de erros graves de escrita. Um percentual importante das respostas (36\%) se limitou a expressar as práticas corporais na forma de uma lista, e apenas 5,5\% apresentaram sentido às suas respostas.

De modo geral, foi possível identificar quatro grupos de respostas:

- O primeiro, com 3, $1 \%$ das respostas, denominado BSEX0 I (Balanço do Saber - Expressão 0I $)^{13}$ ou Não Resposta, engloba os escolares que não compreenderam o enunciado e/ou responderam de maneira incorreta ou arbitrária. Este grupo é predominantemente constituído de meninos "não brancos", com defasagem escolar, de famílias de baixa escolaridade e ocupação precária no mercado de trabalho. Evidenciaram-se grandes dificuldades por parte destes alunos em compreender e se expressar por escrito em sua própria língua. Isto recoloca o problema da função social e pedagógica da escola, e, em certa medida, confirma as teorias da reprodução, ${ }^{14}$ para as quais as origens e desigualdades socioculturais estão na base dos mecanismos que levam as crianças a fracassarem na escola, sem que pressintam como causa as desigualdades a que estão submetidas.

- O segundo, com 32,9\%, cognominado de BSEX02 ou Discurso Mininalista (CHARLOT; BAUTIER; ROCHEX, 1992, p. 176), apre-

13. Essa forma de denominação das categorias, como é possível inferir, é formada pela abreviação dos vocábulos balanço do saber (BS) e expressão (EX), seguido do numeral que indica a quantidade de grupos de respostas identificadas e agrupadas sob a mesma categoria.

14. Referimo-nos fundamentalmente às teorias reprodutivistas desenvolvidas entre os anos de 1960 e 1970, entre outros, por autores como Bourdieu e Passeron (1970, 1975), Baudelot e Establet (1971) e Bowles e Gintis (1976, (98I). Elas procuraram explicar como os alunos são levados a ocupar uma determinada posição em relação ao saber escolar. Recorrem, principalmente, a explicações quanto à origem social, às defasagens socioculturais e às diferenças de ordem econômica e de classe, como causa do fracasso escolar. Para uma apresentação sumária das ideias desses autores, remetemos os leitores ao trabalho de Silva (2007). Para uma crítica a essas teorias, conferir Charlot (2000). 
senta respostas muito limitadas. Os alunos respondem o enunciado utilizando um "discurso mínimo", citando uma lista de práticas corporais aprendidas muito mais por mera imitação do que por meio de um processo de reflexão. Este tipo de discurso foi encontrado nas respostas de meninos das escolas municipais, pertencentes a famílias de baixa renda, "brancos" e com defasagem escolar. Apesar de multirrepetentes, costumam avaliar sua escolaridade de maneira positiva. Neste grupo encontramos ainda as meninas, "não brancas" em idade escolar adequada ou as "brancas" com defasagem escolar. Os poucos anos de formação dos pais, associados à defasagem escolar, estão fortemente associados a alunos que possuem dificuldades em se expressar de forma escrita sobre suas práticas corporais. $\bigcirc$ Exemplo de E04T44A I 8 I5 é típico deste grupo: aluno de uma escola estadual, que se diz "não branco" e pertence a uma família de baixa renda. Sua resposta é plena de erros e minimalista: "Eu adoro jogar futibou e jogar basqete e fazer bisicleta e soutar pipa e jogar volei."

- Oterceiro grupo, com 58,5\%, denominado de BSEX03 ou Discurso Descritivo, também se expressa de maneira pouco detalhada. $\bigcirc$ aluno reconhece as práticas corporais aprendidas e descreve certos aspectos da sua aprendizagem, por exemplo, onde e com quem aprendeu. Mas o seu discurso é pouco modalizado, o que pode se configurar num processo de objetivação. A resposta "coloca o saber como objeto, mas fora da situação ou das atividades através das quais este objeto é constituído." (CHARLOT; BAUTIER; ROCHEX, 1992, p. 176). Trata-se de um tipo de relação epistêmica com as práticas corporais em que os enunciados apresentam "Eu" somente em estruturas simples como, por exemplo, "Eu aprendi 'a' + verbo infinitivo", o que indica uma presença do Eu, mas, ao mesmo tempo, o sujeito ausente do seu próprio discurso. Este tipo de resposta é mais frequente no grupo formado por meninas e em idade escolar adequada. Elas vivem em famílias com melhor formação escolar e renda. Aparecem sentidos ligados à mediação dos pais, à saúde e à competição. Um exemplo desta categoria é o caso de E05T42A09, menina filha de um vigia e de uma babá, autodenominada negra e

15. Sigla utilizada no referido programa Modalise, como forma de identificação em substituição ao nome do(a) aluno(a) pesquisado(a). 
que jamais reprovou: " $\mathrm{R}$ : eu aprendi pega pega e era a única coisa que eu sabia. R: é importante para mim porque era a única coisa que eu sabia fazer. R: quem me ensinou foi uma pessoa muito importante para mim foi minha mãe. R: me ensinaram na rua general Vieira da rosa. É onde que eu moro e lá tem várias brincadeiras."

- Por fim, com 5,5\%, temos o grupo BSEX04 ou Discurso Secundarizado, que apresentou as respostas mais elaboradas, nas quais os alunos reconhecem e descrevem as práticas corporais importantes, como e onde são ensinadas, surgindo, de maneira mais evidente, um sentido para elas. Eles respondem o enunciado refletindo sobre o sentido dos saberes evocados: promover a saúde, fazer amigos, tornar-se atleta, estar próximo aos pais etc. Estas respostas reconhecem e descrevem o aprendizado das práticas corporais mais importantes, onde e quem as ensinou. $\mathrm{O}$ "Eu" é o sujeito do seu discurso por meio de comentários, julgamentos sobre as maneiras como se deu o aprendizado e outras categorizações. Nestas respostas o indivíduo torna-se sujeito, evocando uma distância vis-à-vis dele mesmo, dos outros e da vida, sem manifestar necessariamente um objeto de saber. Este processo de distanciação produz regulação e sentido (CHARLOT; BAUTIER; ROCHEX, 1992, p. 178). Este grupo é bastante heterogêneo, entretanto, reúne parte significativa de meninos e meninas autodenominados "brancos", alunos da escola federal. Encontramos também a presença de meninas que se dizem "não brancas", sobretudo as "negras", que jamais foram reprovadas. Elas pertencem a famílias com formação e renda superior às demais. Contrariam as hipóteses de que as crianças que não se autodenominam brancas teriam mais dificuldades na elaboração escrita, em razão das desigualdades sociais e escolares que historicamente marcam estes grupos. As condições socioculturais marcam o sentido da escola e os resultados escolares, mas não os determinam (CHARLOT; BAUTIER; ROCHEX, 1992).

Este é o caso de E0 IT45A04, aluno autodenominado "não branco", aficionado pelo futebol. Ele demonstra interesse por outras práticas esportivas, como o handebol, destacando a importância do apoio de sua mãe para seu aprendizado. Diz que o futebol é um "esporte para homem" e que foi o seu pai que o teria ensinado. As mediações dos pais e do treinador aparecem em destaque no balanço 
deste aluno. O "sentido futuro" e o "sentido competição", a seguir detalhados, estão presentes. No questionário ele detalha os fundamentos técnicos e as habilidades do futebol que mais Ihe atraem: "o passe, o drible, a meia lua, o balãozinho, a caneta." Deixa transparecer todo seu entusiasmo por aspectos importantes da modalidade: "as estratégias e táticas de jogo, a copa do mundo, o sistema de campeonatos". ○ esporte apresenta-se como um saber, tão importante quanto aqueles estudados na sala de aula: "O futebol é a minha paixão além de Handebol vôlei e basquete elas são importantes porque eu acho que eu tenho futuro. Por que eu pego bem para a minha idade eu acho. Eu só não sei no Handebol eu ainda nunca joguei mas eu aprecio. $\bigcirc$ Handebol vi pela TV mas eu aprendia 48\% com a minha mãe. Mas já o futebol é claro que foi 100\% foi meu pai. Já o vôlei foi a minha mãe e o treinador de EF da I a série e o basquete também."

Ao analisarmos a forma como os alunos expressam a importância das práticas corporais, identificamos cinco categorias de sentido: competição (5,3\%), futuro (8\%), saúde e desenvolvimento (8\%), mediação de professores e pais (15\%) e o prazer $(63,1 \%)$. Estas categorias representam aquilo que os mobiliza a fazer e a aprender práticas corporais. $\bigcirc$ sentido futuro, presente em $8 \%$ dos balanços, remete às expectativas e possibilidades futuras dos alunos em relação às práticas corporais. Veja-se, por exemplo, a resposta de um aluno, já anteriormente referida, que é mobilizado a jogar como "goleiro" no futebol: "o futebol é a minha paixão além de handebol, vôlei e basquete, elas são importantes porque eu acho que tenho futuro. Porque eu acho que eu pego bem para minha idade." O sentido de competição foi encontrado em apenas 5,3\% dos textos. Trata-se da mobilização pelo desafio ou disputa que a prática proporciona, mas em muitos casos isso está relacionado com o fato de ser reconhecido como um vencedor: "a minha foi vôlei e eu aprendi com o professor [nome suprimido] eu gosto do vôlei, e é importante para mim porque eu posso fazer uma aposta e eu posso ganhar e onde foi no colégio que eu aprendi."

Um terceiro sentido presente em $8 \%$ das respostas é o da saúde e desenvolvimento: "Basquete, futebol, handebol e vôlei são importantes porque fazem bem para a saúde para o corpo e para o coração e quem ensinou foi a professora e sozinho explicando como se fazia." Trata-se de um discurso com forte inserção na mídia e nos cursos de formação de professores de Educação Física. O sentido de mediação, encontrado em 15,5\% dos balanços, destaca a importância dos adultos como modelos ou como apoiadores: "Minha atividade mais importante é o vôlei. Eu aprendi na escola... com o meu professor de Educação Física, ele me ensinou com o toque, com o saque e o com o rodízio, e por fim, como se fica na quadra."

Dos sentidos que foram possíveis de serem apreendidos, o do prazer aparece com mais evidência, encontrado em 63,1\% das declarações, e se manifesta em 
respostas do tipo: "soltar pipa e jogo futebol. É legal.", nas quais, geralmente, os alunos expressam a prática e o prazer dela decorrente.

A análise mostra diferentes sentidos quando comparamos o gênero e a autodenominação. Os meninos que se autodenominam "não brancos" são os que menos expressam o sentido das práticas corporais e, quando o fazem, predomina o sentido de futuro, o que reforça a ideia de que a presença de negros e mestiços no futebol e nos esportes em geral poderia servir de modelo na formação do projeto destas crianças. Os dados parecem sugerir uma forte relação das crianças que se dizem não brancas com as práticas corporais.

Quando comparamos as respostas de meninos e meninas, verificamos que entre elas é mais forte o sentido da saúde e desenvolvimento e da mediação, enquanto que entre eles, o sentido de futuro ou competição se faz mais presente. De certa forma, muito do que é expresso pelos estudantes pesquisados são ecos de discursos, práticas e representações socioculturais e historicamente constituídos em torno daquilo que é considerado adequado ou inadequado para homens e mulheres, inclusive no âmbito das práticas corporais. Em nossa sociedade, e por constituir-se em prática altamente organizada e especializada - tanto no que diz respeito às suas regras e normatizações quanto ao intenso processo de treinamento -, o esporte, tradicionalmente, tende a ser um espaço relacionado com o mundo masculino ao exaltar elementos como virilidade, seriedade, desempenho, progresso e excesso. Além desse elemento, no contexto brasileiro, muito em função da crescente movimentação no mercado esportivo, especialmente no futebol, conforme apontam, entre outros, os trabalho de Rial (2006), Souza et al. (2008) e Rocha et al. $(20 \mathrm{I}$ I), a perspectiva de tornar-se um atleta, ou seja, de profissionalização no esporte, representa, especialmente para os meninos, um desejo de ascensão social e de um futuro promissor.

\section{CONSIDERAÇÕES FINAIS}

Em relação aos instrumentos utilizados nesta investigação, entendemos que o balanço do saber e o questionário, apesar de fornecerem boas pistas para se entender os sentidos da mobilização e da aprendizagem dos saberes, ainda são insuficientes para analisar e compreender as histórias singulares dos sujeitos escolares.

Observamos uma relação importante entre as capacidades das crianças de narrar sobre as práticas corporais indicadas como de preferência e as condições sociais e culturais que usufruem. Não há diferenças significativas nas escolhas das práticas e essas mesmas condições, o que sugere algum grau de estandardização das atividades, algo possivelmente vinculado aos consumos da indústria do entretenimento, mas também à frequência à escola e às aulas de Educação Física. 
A essa escolha associa-se o prazer como critério, o que coloca uma questão cuja complexidade se materializa duplamente. Haveria que se saber o quanto tal prazer está associado às demandas de gozo instituídas pela indústria do entretenimento, algo ainda por ser devidamente pesquisado. Por outro lado, o fato dessas atividades serem avaliadas como prazerosas pode ser uma boa possibilidade de, a partir de tal critério, estruturar-se as práticas da Educação Física na escola. Não há êxito educacional se não houver acordos entre professores e alunos, se o prazer, e não o mero gozo imediato, não enformar o acesso aos saberes (corporais).

Os resultados permitem ainda chamar a atenção para a superação dos discursos que tratam a infância e a juventude de forma abstrata, idílica e ingênua, isenta de contradições próprias de uma sociedade também contraditória. É preciso superar a visão simplista, mítica e dicotômica de escola (produtora ou reprodutora), investindo na verificação, pesquisa e produção de inteligibilidades que nos ajudem a explicar e agir sobre os complexos problemas da escolarização, inclusive no que se refere às prática corporais.

\section{Outside School Senses of Corporal Practices by Primary School Students}

ABSTRACT: This paper analyses balances of knowledge and surveys of 585 fourth degrees students from 15 public schools in Florianópolis, Brazil. The aim is to understand imputed senses to outside school corporal practices. The results suggest: a) socio-cultural marks appear as frames of outside school corporal practices; b) the selected outside school corporal practices are very regular, as much group as individual sports; c) inspite students show strong difficulties in writing their reflections about the senses of practices, it's however clear that pleasure is the main sense of that.

KEYWORDS: Balance of Knowledge; Corporal Practices; Primary School; Social Inequality.

\section{Sentidos de las prácticas corporales de afuera de la escuela para los alumnos de la Escuela Primaria}

RESUMEN: El artículo analiza el balance de saberes y los cuestionarios de 585 estudiantes de cuarto año de la primaria de 15 escuelas públicas de Florianópolis, SC, buscando interpretar los significados atribuidos por ellos a las prácticas corporales aprendidas fuera de la escuela. Los resultados muestran que: a) los elementos socioculturales marcan el rumbo de la Educación Física y de las prácticas corporales, b) las prácticas corporales preferidas por los alumnos son de un corte institucional, sobretodo deportes colectivos y individuales, c) a pesar de las dificultades de los estudiantes para reflexionaren por escrito sobre las prácticas corporales, se identificaron categorías relacionadas con el significado de estas prácticas, emergiendo el placer como sentido predominante.

PALABRAS CLAVE: Balance de saber; prácticas corporales; escuela primaria; desigualdades sociales. 


\section{REFERÊNCIAS}

BAUDELOT, C. ESTABLET, R. L'école capitaliste em France. Paris: Maspero, I97I.

BAUTIER, E. Pratiques langagières, pratiques sociales. Paris : L'harmatham, 1995.

BAUTIER, É.; ROCHEX, J-Y. L'expérience scolaire des “nouveaux lycéens". Démocratisation ou massification? Paris: Armand Colin, 1998.

BRASIL. Instituto Nacional de estudos e Pesquisas Anísio Teixeira. (INEP). Resultados do senso escolar, Educasenso, 2007. Disponível em: <http://www.inep.gov.br/basica/censo/Escolar/ Matricula/censoescolar_2007>. Acesso em: 10 abr. 201 I.

BRASIL. Secretaria de Educação Fundamental. Parâmetros Curriculares Nacionais: Educação Física. Brasilia: MEC/SEF, 1997.

BOURDIEU, P.; PASSERON, J-C. A reprodução. Rio de Janeiro: Francisco Alvez, 1975. La reproduction. Paris: Minuit, 1970.

BOWLES, S.; GINTIS, H. Schooling in Capitalist America. New York: Basic Books, 1976.

Siglo XXI, 1981. . La intrucción escolar en la América capitalista. México,

CHARLOT, B.; BAUTIER, É.; ROCHEX, J.-Y. École et savoir dans le Banlieues... et ailleurs. Paris: Armand Colin, 1992.

CHARLOT, B. Du Rapport au savoir: Éléments pour une théorie. Paris: Anthropos, 1997.

Le rapport au savoir en milieu populaire. Une recherche dans les lycées professionnels de banlieue. Paris: Anthropos, 1999.

Mistificação pedagógica: realidades sociais e processos ideológicos na teoria da educação. I. ed. Rio de Janeiro: Zahar, 1979.

Da relação com o saber. Elementos para uma teoria. Porto Alegre: Artmed, 2000.

(Org.) Os jovens e o saber: perspectivas mundiais. Porto Alegre: Artmed, 200 I. CHEVALLARD, Y. Transposition didactique: Du savoir savant au savoir enseigné - Un exemple d'analyse de la transposition didactique. Paris: La Pensée Sauvage, 1998.

CIBOIS, P. L'analyse des données en sociologie. Paris: Presses Universitaires de France, 1983.

DEVOS-PRIEUR, O. Rapports aux savoirs des professeurs d'école et développement des contenus en éducation physique. Étude comparée de quatre cycles de basket-ball au Cours Moyen. 2006. Thèse de Doctorat en Didactique des disciplines scientifiques et technologiques - Université de Toulouse, Toulouse, 2006.

DUGAS, E. Des pratiques sociales aux pratiques scolaires en EPS: des logiques de scolarisation plurielles. Revue Française de Pédagogie, n. 149, 2004, p. 05- 17.

FOUCAULT, M. As palavras e as coisas. São Paulo: Martins Fontes, 2007. 
GARNIER, A. Le rapport au savoir de l'enseignant dans un enseignement usuel en gymnastique. In: AMADE-ESCOT, C. (Dir.). Didactique de l'éducation physique : État des recherches. Paris: Revue EPS, 2003. p. 225-253.

JOURDAN, I.; TERRISSE, A. Rapport au savoir et logique de professionnalisation en formation initiale en EPS à l'IUFM Midi-pyrénées. Recherche et formation, Lyon, n. 50, p. 23-36, 2005.

LAZZAROTTI FILHO, A. et al. O termo práticas corporais na literatura científica brasileira e sua repercussão no campo da Educação Física. Movimento, Porto Alegre, v. I6, n. I, p. | |-29, jan./mar. 2010.

MAUSS, M. As técnicas do corpo. In: Sociologia e Antropologia. São Paulo: Cosac Naify, 2003, p. 399-422.

MENEZES, E. T.; SANTOS, T. H. dos. Distorção idade-série (verbete). Dicionário Interativo da Educação Brasileira. São Paulo: Midiamix Editora, 2002. Disponível em: <http://www. educabrasil.com.br/eb/dic>. Acesso em: 13 abr. 201 l.

MOSCONI, N.; BEILLEROT, J.; BLANCHARD-LAVILLE, C. Formes et formations du rapport au savoir. Paris : L'Harmattan, 2000.

RIAL, C. S. Futebolistas brasileiros na Espanha: emigrantes porém.... Revista de Dialectología y Tradiciones Populares, Madrid, v. 61, n. 2, p. 163-190, 2006.

ROCHA, H. P. Al. et al. Jovens esportistas: profissionalização no futebol e a formação na escola. Motriz: Revista de Educação Física, Rio Claro, v. 17, n. 2, p. 252-263, abr./jun. 201 I . ROCHEX, J-Y. Le sens de l'Expérience Scolaire. Paris, PUF, 1995.

A noção de relação com o saber: convergências e debates teóricos. Educação e Pesquisa, São Paulo, v. 32, n. 3, p. 637-650, set./dez. 2006.

SILVA, T. T. da. Documentos de identidade: uma introdução às teorias do currículo. 2. ed. I I . reimp. São Paulo: Autêntica, 2007.

SOUZA, C. A. M. et al. Difícil reconversão: futebol, projeto e destino em meninos brasileiros. Horizontes Antropológicos, Porto Alegre, v. I4, n. 30, p. 85- I I I, 2008.

Recebido em: 6 mar. 2012 Aprovado em: 16 set. 2012

Endereço para correspondência: Fábio Machado Pinto Universidade Federal de Santa Catarina Departamento de Metodologia do Ensino Centro de Ciências da Educação, Campus Universitário da Trindade 88040-900 - Florianópolis, SC - Brasil 